called "premonitory stage" constitutes in very fact the "true first stace" of the disease. As far as the nomenclature goes, there is nothing in the innovation to cast a slur on the acumen of our forefathers. The whole affair is, in truth, a mere dispute of words. For those observant predecessors held that the "premonitory stage" was a condition of things involving, as a necessity, further evolution-advancement, in a word, to the fully formed disease. They believed, in other terms, that the dyspeptic group they marked "premonition" was, as matter of fact, "incipient actuality."

The real difference between the combatants for a "premonitory" and for a "true first" stage, consists in the more precise notion the advance of knowledge has enabled our contemporaries to give of what actually constitutes the one or the other. Dwindling fat, failing weight, impaired strength, modified temperature, and perverted innervationthe incipient group of the pathologist of the present dayis a definite combination, announcing, in the majority of cases, the commencing mischief of tuberculisation, destined to run its habitual course.

Now $I$ have no hesitation in saying that $I$ accept the doctrine of those who teach that the group of conditions just put together announces, not the imminence more or less sure, but the actual presence, of the disease. But the difficulty remains, that it is not now, nor conceivably will it ever become, possible to fix the moment when the actual deposition of the first particle of tubercle occurs. Where is the demonstration that in the "premonitory" or "true first" stage (call it which you will) actual tubercle is not as early in the field as the asserted evidence of the stage itself? To demonstrate that it is not would require-

First, that the characters of the said stage were solidly fixed and capable of positive diagnosis.

Secondly, that it was shown the like combination of characters was foreign to the outbreak of all other diseases. In the present state of knowledge, we are not able to affirm that everyone who loses fat, undergoes a change in the distribution and activity of his calorification, and gets weak, is necessarily on the high road to tuberculous destruction of his lung-substance.

Thirdly, that, through accidental contingencies, deaths should occur in goodly number during this stage, so that in process of time an imposing mass of post-mortem evidence might be appealed to, proving in such cases the uniform absence of a particle of tubercle.

I need hardly say that nothing of all this has ever yet been established or ever yet been done.

But, gentlemen, in glancing at this moot question in the present place, I have wandered into a sort of digression. For, in point of fact, it matters little in the investigation before us whether the "premonitory" or " true first" stage view is destined to carry the day; our point is to ascertain whether the earliest manifestations of morbid activity, however the group be designated, that culminate in phthisical destruction, set in more frequently and more readily in persons whose health is "below par," or in those in whom it is "good." Of course, we know what the unhesitating answer would commonly be to a question of this sort. Probably it may be looked on as a piece of daring medical heresy to utter a word calculated to shake the timehonoured dogma of the intimate and necessary dependence of tuberculous disease on pravity of constitution-a "below par" state induced by over-toil, excesses of various kinds, wearing anxiety, \&c. But many a long-accredited notion has proved but a fable in the end; and the present dogma seems to me to rest on no better basis than a mixture of imperfect theory, preconceived ideas, and loose observation. The theory is, that the state induced by over-toil, \&c., must be favourable to the nutrition vices concerned in the tuberculising process. But suppose $I$ choose to assume the very reverse of this, and say that, for aught we know to the contrary, the vitally deteriorated and chemically altered conditions of the nerves and blood of an overworked and worn man may be vitally and chemically antagonistic to, instead of promotive of, the specific perversions belonging to the outbreak of tuberculisation, is my proposition less tenable than that of my adversary? Not a whit. As regards preconceived ideas and loose observation, the ordinary fashion of proceeding is this: a man becomes consumptive; he was dissipated, or he was over-anxious and over-worked, \&c., and out comes the sapient self-gratulation, "Ah! I knew it ; I always said it; poor fellow, he was so overdone," \&c. while the thousands who have been similarly overworked, and who have nevertheless gone to their graves free from a trace of tubercle, are conveniently forgotten. No; that there is something wrong in the so-called "below par" state cannot for a moment be doubted; but whether that something wrong struggles to promote, or tends to prevent, the diathetic disturbances belonging to tuberculisation, is at the present day an unsolved mystery.

As to Acute Specific Diseases and their alleged attraction for organisms in a "below par" state of health, some reasons have already been given for questioning the perfect correctness of the common belief. You have heard evidence tending to make it probable that the proclivity to receive these diseases is greatest among the healthy. At all events, the disposition to appropriate the floating poisons of epidemic diseases seems quite as marked among the strong as among the careworn, exhausted, and underfed. The usual argument that cholera, for example, is attracted by a deteriorated condition of health, because it so largely destroys the poorer classes, seems, when sifted, to carry with it but little weight. For, in the first place, it has not, so far as I am aware, been shown that the number of choleraic deaths is seriously greater, in proportion to their numbers, among the poorer than among the richer orders. Next, it is forgotten that, though a "below par" state of health, brought on by the use of insufficiently reparative food and by privations of various kinds, is escaped by the rich, they are exposed to the risks of many other quite as active causes of weakened vital energy. Thirdly, the much greater chance of effective introduction of the poison occurring among the poor from overcrowding and allied social mischiefs, has not, it would seem to me, been accorded its due place in the argument.

(To be concluded.)

\section{REMARKS ON SCIENTIFIC THERAPEUTICS.}

Being a Portion of a Lecture delivered at Guy's Hospital.

By SAMUEL WILKS, M.D., F.R.S.,

LECTURER ON MEDICINE.

(Concluded from page 226.)

REMEMBER, I have nothing to say theoretically against a scientific use of medicine, but I deny that, at the present day, we have sufficient ata to guide us; and thus the experienced man is the best practitioner. But just now I had an example of this. A young lady was seized with acute mania. An old and experienced man, of no scientific attain ments, placed her in a room with an attendant, administered aperients, and did all that the art admittedly allows. The friends, not satisfied, called in a younger and cleverer man, who commenced to treat the case secundum artem, first by shaving the head and applying a blister all over it, and, secondly, by administering large doses of morphia. The girl was driven raving mad by the method. "But surely," said the doctor, "such remedies were suggested-the counterirritant for the excited brain, and the opium to procure sleep." Take that common disease, rheumatic fever. It is evident that the predilection by one practitioner for alkalies is supported by the sour perspiration and the hypothetical lactic acid in the blood, whilst the advocacy of quinine and iron is stimulated by the belief that rheumatism is a nervous disease. Then, again, we shall find one medical man prejudiced in favour of particular remedies when his mind is upon cell growth, another in favour of medicines which alter the chemical relations of the blood, and another in favour of those which act on the vaso-motor system of nerves. The vaso-motor theory of therapeutics is the latest and simplest, for by the application of heat and cold you may, by acting on the nerves, influence the amount of blood-supply to a part, and so, by altering all nutritive processes, cure any disease which flesh is heir to.

In all these cases unproved theories have had greater weight than well-supported facts. The greatest calamity, however, arises from the fact, not that men disbelieve in the efficacy of remedies, but that they practically repudiate

$$
\text { II } 2
$$


these in individual cases, because their theories oblige them to consider the medicines unsuited to the particular case in hand. They take their ideas of the action of medicines according to the effects of these in health, and then apply their observations to cases of disease. Thus it is that there is no complaint but what is treated with ammonia and brandy. The case under consideration, it is said, will not bear what is called the routine plan; and so old and approved remedies are discarded, and stimulants supply their place on account of the patient's weakness. I constantly see, for example, cases of pneumonia where I have every reason to believe that some old-fashioned medicines would be useful, but stimulants are administered instead (with a blister, which I believe does more harm than good). The medical attendant is a great believer in physic, and he by no means treats patients with stimulants; but this particular patient was so low that he seemed to require them. Acute rheumatism with chest complication I see treated in exactly the same manner. In fact, if weakness is to be treated, and not the disease, ammonia and brandy are pretty nearly universal remedies. Thus, within the last two or three weeks, I have had the opportunity of seeing the following diseases treated in exactly the same way with these two drugs: typhus, pneumonia, delirium tremens, rheumatic fever, cynanche, scarlatina, typhoid, hepatic ascites, erysipelas, small-pox, morbus cordis, pyæmia, bronchitis, diphtheria, carbuncle, and pleuritis, besides a number of nameless chronic maladies. Now and then I have had the opportunity of contrasting a truly remedial method with this let-alone system, and often to the advantage of the former. Thus, on three separate occasions, I have seen patients with acute cynanche tonsillaris, where the terrible word "malignant" had been associated with the disease, and consequently large quantities of port wine were being "poured in," and ammonia and bark administered as medicines; and in all these cases, at my instigation, these means were discontinued, and the patients were put on the old-fashioned plan of a purge, saline mixture with antimony, and some Dover's powdex with calomel. In all the rapid subsidence of the symptoms was most marked. In croup I find that some practitioners still keep to the old antimony emetic, and the result, in my opinion, contrasts most favourably with that which is seen in the hands of the "trimmers," who are content to order a little harmless medicine. For between the bold practitioners who either use active medicines, on the one hand, or more active stimulants, on the other, are the timid men, who find it safest to take a middle course, and, by splitting the difference, believe that they haze pursued a truly scientific method.

A good example of the evils of no treatment occurred to me lately in a case of pleuritic effusion. A gentleman requested me to see one of his men, in this neighbourhood, who was suffering from this complaint, and whose appearance was such that $I$ had considerable doubt as to the possibility of his recovery. I stated to the medical man whom I met that I was well satisfied with the orthodox method of treatment-namely, diuretics, some mercury and opium, and counter-irritants to the chest. I was met with the customary answer, that people cannot bear now what their fathers could (a theory unsupported by any good facts), and that he feared all the remedies I had mentioned would depress the patient; and thus he had been writing the usual prescription of ammonia and brandy. I then requested that I might have the man under my charge in the hospital, where I immediately stopped the stimulants and put him on the plan I had recommended. He remained in a very precarious state for a few days, and then rapidly recovered.

Making mention of counter-irritation reminds me that some capital essays have been lately written on this subject, showing the absurd reasons which suggested the method, and the absence of a rationale in the minds of those who still adopt it. The case serves me for illustration, for I have the strongest belief in the efficacy of counter-irritants, although I have no very positive idea of their action.

The error of allowing what is called reason or common sense to guide you, when the data on which to form a right opinion are wanting, is never better seen than in the simple case of dyspepsia which is daily before us. A patient states that his food does not digest, and that he is troubled with acid eructations. For this acidity he may have been recommended alkalies, or may have taken them on his own account; and yet very frequently the remedy which is the best tonic for his stomach is a mineral acid. The case, very often, is not one primarily of gastric weakness, but of nervous or cerebral dyspepsia. One of the commonest examples of what is supposed to be a rational use of medicine is the administration of iron. In the majority of instances, $I$ have every reason to believe, it is given because the patient looks pale. The idea is that pallor implies a deficiency in the red colouring matter of the blood, and that the colour is due to iron; therefore that person wants iron who is pale, or, to use the cant phraseology of the day, because he has a deficiency of red particles in his blood. This is a piece of scientific therapeutics which the patient can understand, and so doctor and patient are pleased with a very pretty piece of sentiment. I am not saying a word against iron, which $I$ consider is one of the most valuable medicines in use, and I know that in chlorosis it is our best remedy; but $I$ also know that this disease is curable by aloetic and otber medicines, and I can inform you, too, that in many other forms of anæmia it is a remedy which is utiterly useless. There is a class of cases which, for want of a better name, we are forced to designate idiopathic anæmia; patients with this disease are saturated with iron by every fresh doctor they consult, but without the slightest benefit. I hope to be able to tell you of cases which are benefited by iron, but I cannot teach you that because a man looks pale he therefore requires this metal.

I might go on thus through the whole category of diseases and drugs, and show how deceitful is the method of administering the latter for a supposed connexion between them and the disease. I might tell of the hundreds of persons with paralysis taking strychnine because it is the correct remedy, but without any benefit to their symptoms; also of the injurious effect of the indiscriminate use of chloral and opium. If your patient cannot sleep, or experiences pain, these of course are the remedies suggested; but you may merely benumb or stupefy him, without tonching the cause. I think the universal use of chloral in every possible malady presents a most pitiable exhibition of the weakness of our therapeutics. Everyone who is ill has a pain or an ache, or is irritable and restless, and at length we have got a panacea. What can be thought of our art when we are so ready to catch at a new drug and administer it to everybody. Now it is chloral, yesterday it was carbolic acid, and before that bromide of potassium. Just as, two years ago, everyone was taking this last medicine, so now everyone is swallowing chloral. It is a most sorry patchwork piece of business. What I mean is this, that a man who is always ready to accept the last new remedy can have no great confidence in his former methods. And yet it is this very man who is said to be a believer in medicine. No greater sceptic can exist. When meeting with such a person I myself have been charged with scepticism; and, if you will allow me, I will refer for a moment to a personal matter in connexion with this subject. All my life I have been constantly taunted with a want of faith in drugs, and yet all the while $I$ have had more real confidence in $\mathrm{my}$ remedies than nine out of ten of the men who have charged me with the fault. I have never said a word to encourage such an opinion, and am at a loss to understand its widespread existence.*

I believe therefore, most sincerely, that I am giving you the best advice when I request you to gain all the knowledge you can from your teachers as to the best modes which experience has discovered to combat disease, and at the same time to make similar observations for yourself. You may speculate, if you please, as to what is meant by remedies such as calomel, antimony, or digitalis, being called "antiphlogistic"; but if you wait until you know their modus operandi, or what special symptom indicates their use, you will be losing some of the best remedies in the Pharmacopoia. I believe that I have got more credit from the use of digitalis than any other medicine, simply because

* My only explanation is that it is due to the belief in the incapability of men in our profession doing more than one thing; and just as the tailo who makes your coat cannot by any possibility excel in trousers, so the doctor who cures rheumatism can know nothing of dyspepsia, or he who can advise for epilepsy cannot at the same time be clevtr with children. So because 1 , fortunately or unfortunately, had m re than the usual oppor tunities of devoting myself to pathology, so 1 might be able to tell how rotten a man's inside had become, but could not by any chance have notion of any means to rescue him from decay; for what possible connexion Bright's kidney and jalap powder? Thus have I been a vietim of vulgar error. 
the patient was considered too weak to bear it before my advice was sought; and during the last two years I have seen three cases of chronic cerebral affection cured by mercury, where all the ordinary nervine remedies which the symptoms had suggested had failed. Remember, I say not a word against a sound and scientific therapeutics, and I might admit that in some exceptional cases we have a glimmering of reason associated with the mode of cure; and I rejoice also that we have a journal like the Practitioner, which is arduously endeavouring to attain the object we all have in view. That our treatment is empirical, and not scientific, is beyond all cavil. This is evident from the fact that quackery abounds, and that success in our profession is not proportional to a man's knowledge. If a thorough appreciation of symptoms and a rational application of drugs were necessary to the cure of any malady, it would follow that the better educated a man was, the more successful would he be. Quacks would fade from the earth; for their practice would at once necessitate the coroner's inquiry. So far from theory going hand in hand with practice, it is exactly the reverse; and thus you will find that all systems of quackery have their foundation in, or are associated with, a theory; and even with the more orthodox practitioners it is those who nearest approach the border. land of charlatanism who can inform their patients of the "reason" why they select their medicines. Every quack knows it is the theory, and not the practice, which pleases. Thus, Morison's pills would not be swallowed unless they "purified the blood"; nor Parr's life pills, unless they "sustained the vital fluids." I have already alluded to the homœopathic doctrine, which ignores pathology and treats only symptoms. Such a doctrine I believe is quite fatal to the system. But I have something even worse to think about it; for I have much reason to believe that the mysterious dogma, " similia similibus curantur," much assists its supporters in administering their physic and the patients in swallowing it. That this inexplicable doctrine guides them I do not for a moment believe. It is far too subtle to handle: it eludes you the moment you think you have it fairly in your grasp. And this, I take it, must be the case even with its supporters; for you will find that they by no means have a rule to guide them as to what are or what are not the essential symptoms of a complaint, but they are content to take that one which is evident to the vulgar eye, and work upon it. For example, they do not appreciate all the symptoms of scarlet fever, but recognise only the outward condition of red skin with sore-throat, and consequently give belladonna. They do not discuss the meaning of the general symptoms of small-pox, but, in a most superficial manner, discern only the pustules; and they accordingly administer antimony, for the sole reason that it produces a rash resembling that of variola: this remedy they declare will arrest the maturation. Considering the prevalence of these two epidemics in England, and the number of homoopathic practitioners, it is surprising that the Registrar-General has to return so large a bill of mortality every week. So utterly regardless of the nature of disease are these practitioners, that, when writing on such an affection as morbus Addisonii, they will detail the appropriate remedies to cure it, which is tantamount to reconverting the utterly destroyed supra-renal capsules into healthy ones. I judge from my knowledge of the practice of one or two homcopathists that they do not allow their own principles to guide them. I do not wish to be uncharitable, and would in nowise quarrel with any man because he holds a different opinion from my own; but honesty is a matter of morals, and I know that these gentlemen will give large doses of quinine and opium in cases where experience alone must have been their guide, and wbich, after the most subtle or sophisticated handling, their doctrine could not have suggested. I know that no homoopathic doctor would ignore large doses of iodide of potassium in syphilis, althouch he is fully aware that the drug has no tendency to produce nodes on the bones or lumps in the testes, but rather the reverse. In a case of which $I$ had a knowledge a homoeopathic practitioner administered quinine in large doses and used morphia by subcutaneous injection, and speedily cured the patient. When asked what I should have done, I replied, I should have prescribed exactly the same; but, in turn, requested to know why he had been preferred to me; and the answer was to the effect that he had acted on principle-that is, he knew why quinine cured neuralgia, and I did not; I had gained my knowledge from experience, while he could have predicated the specific action of the drug as deduced from scientific principles. Well, I will merely make this comment upon it. There is a wellknown American gentleman of the name of Barnum, and he has written a most interesting and instructive book on what he calls "Humbug." The author says that a man who sells an article not worth the money is a thief or a cheat; but he who gives you value for your money, but entices you to deal with him on account of some plausible tale associated with his goods, belongs to the class of whom he discourses. He alludes, amongst other examples, to a late well-known character, M. Mangin, who made a fortune in Paris by selling lead pencils at two sous apiece. These were excellent pencils, and well worth the money; his customers were therefore not cheated, and he was not an impostor. He did, however, richly deserve anctiher name; for he chose to attract his customers by wearing a helmet and beating a drum, and thus pocketed a fortune while his poorer lead-pencil brethren were starving. I dare say Parr's life pills are worth the money, but it is the word "life" which encourages the public to swallow them. So, really, if it be true that some homcepathic doctors foist upon their patients an inscrutable doctrine to tickle their fancy, and at the same time administer such good physic as their experience has shown them to be useful, such men are by no means to be called impostors, according to the high authority of Mr. Barnum, but they would rather come under the other appellation which forms the title of his book.

This, then, is another argument against theory in therapeutics: that it forms the stronghold of all the false systems; that charlatanism is entirely dependent upon it; and that the nearer the tendency of anyone to quackery in orthodox medicine, the louder is his assumption of a fanciful doctrine to support him. I hope you will not mistake my meaning. I do not wish to underrate the researches of those who are investigating the actions of medicines, but would hail the time when these could be found to bear fruit, for then would commence a new era in medicine. I do, however, feel that, with our present ignorance of the meaning of symptoms and our oreater ignorance of the actions of drugs, we should do far better to administer remedies in accordance with experience; and I say this the more emphatically, because I every day see that fanciful reasons engendered solely in the brain of the doctor have caused him to lay aside many old and most approved remedies. I hope, however, before I have ceased teaching at this school, to be able to adopt very different language from this, and enforce some more strictly scientific rules of treatment. Nothing is more difficult than to shake off the trammels which onx own imaginations impose upon us; and thus you will find the good work done by such men as the great Sydenham, the father of English medicine, was by the simple observation of nature and of the operations of the remedies which he gave, at the same time overthrowing the various fanciful methods which he found prevailing in connexion with all diseases. In various places of his writing you will find such passages as this, with which I shall conclude my lecture: "For, without practical observation, that which seems reasonable to me or any other person perchance will be nothing else but the shadow of reason, or a phantasm-that is, mere opinion. And the oftener I converse with men, I am the more confirmed how dangerous it is even for those that are the most acute to rack their brains, and, as it were, inflame them, in the search of any art or science, unless they constitute matter of fact as judge and umpire of truth and falsehood."

West Norfolk and LynN Hospital. - $\mathrm{Mr}$

Kendall has resigned the appointment of senior surgeon to the above institution after having held it for fifteen years. At the annual meeting of the governors on the 14th inst. the following resolution was passed and forwarded to Mr. Kendall :-“'That this meeting of Governors begs to convey to Mr. Kendall their cordial regret at the great loss the hospital has sustained by his resignation as surgeon, and they trust he may long continue in the enjoyment of better health ; and, as a mark of their estimate of his invaluable services to the charity, they request him to accept the appointment of consulting surgeon, and to be a lifegovernor." 